\title{
Standard Methodology for Evaluating Membrane Performance in Osmotically Driven Membrane Processes
}

\author{
Tzahi Y. Cath ${ }^{\mathrm{a}, *}$, Menachem Elimelech ${ }^{\mathrm{b}}$, Jeffrey R. McCutcheon ${ }^{\mathrm{c}}$, Robert L. McGinnis ${ }^{\mathrm{d}}$, Andrea Achilli ${ }^{\mathrm{e}}$, \\ Daniel Anastasio ${ }^{c}$, Adam R. Brady ${ }^{a}$, Amy E. Childress ${ }^{\text {f }}$, Isaac V. Farr ${ }^{\mathrm{g}}$, Nathan T. Hancock ${ }^{\mathrm{d}}$, Jason Lampi ${ }^{\mathrm{f}}$, \\ Long D. Nghiem ${ }^{\text {h, }}$, Ming Xie ${ }^{\mathrm{h}}$, Ngai Yin Yip ${ }^{\mathrm{b}}$
}

a Colorado School of Mines, USA

b Yale University, USA

c University of Connecticut, USA

d Oasys Water, USA

e Humboldt State University, USA

${ }^{\mathrm{f}}$ University of Nevada, Reno, USA

${ }^{g}$ Hydration Technology Innovations, USA

${ }^{\mathrm{h}}$ University of Wollongong, Australia

\section{H I G H L I G H T S}

- In forward osmosis and PRO, membrane testing conditions and protocols are commonly inconsistent.

- It is difficult to compare the performance of old and new generation forward osmosis membranes.

- A standard method for characterizing forward osmosis membranes is proposed.

- Results from a round-robin test of the method by seven independent laboratories are presented.

- Testing results of two commercial membranes were consistent between laboratories when using the methodology.

\section{A R T I C L E I N F O}

\section{Article history:}

Received 20 February 2012

Received in revised form 24 June 2012

Accepted 9 July 2012

Available online 11 August 2012

\section{Keywords:}

Osmotically driven membrane process

(ODMP)

Forward osmosis (FO)

Pressure retarded osmosis (PRO)

Osmotic dilution (ODN)

Desalination

Water reclamation

\begin{abstract}
A B S T R A C T
Osmotically driven membrane processes (ODMPs) such as forward osmosis (FO) and pressure retarded osmosis (PRO) are extensively investigated for utilization in a broad range of applications. In ODMPs, the operating conditions and membrane properties play more critical roles in mass transport and process performance than in pressure-driven membrane processes. Search of the literature reveals that ODMP membranes, especially newly developed ones, are tested under different temperatures, draw solution compositions and concentrations, flow rates, and pressures. In order to compare different membranes, it is important to develop standard protocols for testing of membranes for ODMPs. In this article we present a standard methodology for testing of ODMP membranes based on experience gained and operating conditions used in FO and PRO studies in recent years. A round-robin testing of two commercial membranes in seven independent laboratories revealed that water flux and membrane permeability coefficients were similar when participants performed the experiments and calculations using the same protocols. The thin film composite polyamide membrane exhibited higher water and salt permeability than the asymmetric cellulose-based membrane, but results with the high permeability thin-film composite membrane were more scattered. While salt rejection results in RO mode were relatively similar, salt permeability coefficients for both membranes in FO mode were more varied. Results suggest that high permeability ODMP membranes should be tested at lower hydraulic pressure in RO mode and that RO testing be conducted with the same membrane sample used for testing in FO mode.
\end{abstract}

(c) 2012 Elsevier B.V. All rights reserved.

\section{Introduction}

Osmotically driven membrane processes (ODMPs) are innovative technologies with applications in water treatment and desalination

\footnotetext{
* Corresponding author. Tel.: +1 303273 3402; fax: +1 3032733413

E-mail address: tcath@mines.edu (T.Y. Cath).
}

(forward osmosis, FO), power generation (pressure retarded osmosis, PRO), and dewatering of aqueous solutions (direct osmotic concentration, DOC, and osmotic dilution, ODN) [1-4]. These methods utilize osmotic pressure difference between a dilute feed solution and a concentrated draw solution to induce mass transport of water through semipermeable membranes from the feed stream into the draw solution. Increasing demand for water and electricity and encouraging 
results from ODMP studies in recent years, have accelerated the development of ODMP technologies, including a flurry of membrane development work [5-21] intended to enable further improvement and commercialization of ODMPs.

Many studies examined the performance of new membranes designed specifically for ODMPs for various applications. These investigations used a variety of membranes, different feed and draw solutions, different testing apparatuses, and different operating conditions, including flow rates, temperatures, and concentrations. Wang et al. [22] summarized results from 16 studies, none of which was performed under similar conditions. As a result, the reported water and salt fluxes are scattered over a broad range. Testing conditions reported in recent publications on FO membrane development [7,8,12,13,15,17-19,23-29] are summarized in Table 1. It can be seen from the data that both temperatures and draw solution concentrations are not consistent, and therefore, make membrane performance difficult to compare. Furthermore, in many cases the batch designation of the manufactured OMDP membranes is not indicated, making it more difficult to compare performance between membranes.

While ODMPs may appear simple to operate and test, slight variations in operating conditions can have profound influence on their performance (i.e., water flux and solute rejection). Performance differences in ODMPs may be more pronounced than in reverse osmosis (RO) or nanofiltration (NF) because two streams (feed and draw solutions) affect the chemical and physical conditions on both sides of the membrane, as opposed to only one side in RO and NF. As new ODMP membranes are being developed, standard protocols should be established for testing the permeability and selectivity of the membranes. This task is especially critical when several membrane configurations are being pursued for ODMPs, including hollow fiber and flat-sheet thin-film composite (TFC).

The membrane community has already accepted standard testing protocols to allow performance comparison between high pressure membranes. For example, brackish water RO membranes are typically tested with feed pressure of $15.5 \mathrm{bar}$ ( $225 \mathrm{psi}$ ), feed temperature of $25{ }^{\circ} \mathrm{C}$, feed solution of $2000 \mathrm{ppm} \mathrm{NaCl}$, and specified water recoveries for different membrane element sizes. Seawater RO membranes are typically tested at 55.1 bar $(800 \mathrm{psi}), 25^{\circ} \mathrm{C}$, and with $32,000 \mathrm{ppm} \mathrm{NaCl}$ feed solution. $\mathrm{NF}$ membranes are usually tested with $\mathrm{MgSO}_{4}$ feed solution. The main objective of this paper is to establish standard testing methods and protocols for evaluating the performance and integrity of ODMP membranes. This paper introduces protocols that should be used to facilitate comparison between different ODMP membranes. The testing protocols were evaluated by seven independent laboratories with two types of ODMP membranes: TFC and asymmetric polymeric membranes.

Table 1

Testing conditions reported in recent publications on FO membrane development.

\begin{tabular}{lllll}
\hline Draw solution & DS concentration & Feed & Temp $\left({ }^{\circ} \mathrm{C}\right)$ & Reference \\
\hline $\mathrm{NaCl}$ & $1.5 \mathrm{M}$ & DIW & $23 \pm 1$ & {$[17]$} \\
$\mathrm{NaCl}$ & $0.5,1,2,3,4,5 \mathrm{M}$ & DIW & $22 \pm 0.5$ & {$[23]$} \\
$\mathrm{NaCl}$ & $0.5,0.75,1.0 \mathrm{M}$ & $\mathrm{NaCl}(10,40,80 \mathrm{mM})$ & 25 & {$[24]$} \\
$\mathrm{NaCl}$ & 0.5 & DIW & 23 & {$[25]$} \\
$\mathrm{MgCl}$ & $0.5-3.5 \mathrm{M}$ & DIW & 23 & {$[15]$} \\
$\mathrm{NaCl}$ & $0.5,2 \mathrm{M}$ & $100 \mathrm{ppm} \mathrm{NaCl}$ & 23 & {$[26]$} \\
$\mathrm{MgCl}_{2}$ & $0.5-4 \mathrm{M}$ & DIW & 23 & {$[13]$} \\
$\mathrm{MgSO}_{4}$ & $150 \mathrm{~g} / \mathrm{L}$ & $35 \mathrm{~g} / \mathrm{L} \mathrm{NaCl}$ & 20 & {$[12]$} \\
$\mathrm{NaCl}$ & $3 \mathrm{M}$ & DIW & 20 & {$[8]$} \\
$\mathrm{NaCl}$ & $1-2.5 \mathrm{M}$ & DIW/3.5\% NaCl & $22 \pm 0.5$ & {$[27]$} \\
$\mathrm{NaCl}$ & $0.5,2 \mathrm{M}$ & $100 \mathrm{ppm} \mathrm{NaCl}$ & 23 & {$[7]$} \\
$\mathrm{MgCl}$ & $0.5-3 \mathrm{M}$ & DIW/10 mM NaCl & 23 & {$[28]$} \\
$\mathrm{NaCl}$ & $1.5 \mathrm{M}$ & DIW & $25 \pm 0.5$ & {$[18]$} \\
$\mathrm{NH}_{4} \mathrm{HCO}_{3}$ & $1.5 \mathrm{M}$ & DIW & $25 \pm 0.5$ & {$[18]$} \\
$\mathrm{MgCl}_{2}$ & $5 \mathrm{M}$ & DIW & 23 & {$[29]$} \\
$\mathrm{NaCl}$ & $0.5 \mathrm{M}$ & DIW & 25 & {$[19]$} \\
\hline
\end{tabular}

a Deionized water.

\section{Governing equations in ODMPs}

Water flux $\left(J_{w}\right)$ during osmosis through a semipermeable membrane can be quantified by:

$J_{W}=A\left(\pi_{D}-\pi_{F}\right)$

where $A$ is the water permeability coefficient, $\pi_{D}$ is the osmotic pressure of the draw solution at the membrane interface and $\pi_{F}$ is the osmotic pressure of the feed solution at the feed-membrane interface. This equation, however, assumes a well-stirred system without the presence of boundary layers, which in ODMPs occur on both the feed and draw solution sides of the membrane and inside the porous support layer of the membrane. McCutcheon et al. [30,31] presented a model for osmotic flux across a dense, symmetric membrane:

$J_{W}=A\left[\pi_{D, b} \exp \left(\frac{-J_{W}}{k_{D}}\right)-\pi_{F, b} \exp \left(\frac{J_{W}}{k_{F}}\right)\right]$

where $\pi_{D, b}$ and $\pi_{F, b}$ are the bulk osmotic pressures of the draw and feed solutions, respectively, and $k_{D}$ and $k_{F}$ are the mass transfer coefficients on the draw and feed solution sides of the membrane, respectively. This implicit flux model incorporates concentration polarization moduli that account for boundary layer phenomenon on both sides of the membrane. The solutes are rejected on the feed side of the membrane, resulting in an increase in local concentration near the membrane interface on the feed side, and dilution (a negative exponential term) on the draw solution side of the membrane as water that permeates the membrane dilutes the draw solution at the downstream interface.

However, even Eq. (2) is incomplete as today's desalting membranes are asymmetric and comprise a thin selective layer and a thick, nonselective porous support layer. Because the effective osmotic pressure of a solution is only established at the interface with the selective layer, the asymmetric structure of a membrane ensures that one of the boundary layers occurs within the support layer, resulting in internal concentration polarization (ICP) $[30,32,33]$. To account for this change, an effective mass transfer coefficient, $k_{\text {eff, }}$ was defined which takes into account the impact that the porous support layer has on mass transfer:

$k_{\text {eff }}=\frac{D_{S} \varepsilon}{\tau \delta}=\frac{D_{S} \varepsilon}{\tau t}$

Here, $D_{s}$ is the diffusivity of the solute, $\delta$ is the thickness of the boundary layer (here assumed as the thickness of the support layer), and $\varepsilon, \tau$, and $t$ are the porosity, tortuosity, and thickness of the porous support layer of the membrane, respectively. For the specific case in which the porous support layer is in contact with the draw solution (i.e., the FO mode), Eq. (2) above becomes:

$J_{W}=A\left[\pi_{D, b} \exp \left(\frac{-J_{W}}{k_{D, e f f}}\right)-\pi_{F, b} \exp \left(\frac{J_{W}}{k_{F}}\right)\right]$.

ICP has been investigated in many studies and it is widely considered to be one of the significant obstacles to further development of ODMP. Salt flux during ODMP is also a major factor in the performance of the processes. Recent studies provided thorough experimental and modeling approaches to predict forward and reverse diffusion of electrolytes through semipermeable membranes during ODMP [34-39]. One useful equation that relates the water flux, $J_{w}$, and reverse solute flux, $J_{s}$, has been developed independently by Phillip et al. [36] and Tang et al. [40]:

$\frac{J_{W}}{J_{S}}=\frac{A}{B} n R_{\mathrm{g}} T$

where $B$ is the solute permeability coefficient of the membrane, $n$ is the number of species that the draw solute dissociates into (e.g., $n=2$ for 
$\mathrm{NaCl}), R_{\mathrm{g}}$ is the gas constant, and $T$ is the absolute temperature. This relationship indicates that the ratio of the water and reverse salt flux is a function of the transport properties of the membrane active layer and is independent of the structure of the support layer.

It can be seen from Eqs. (1)-(5) above that the membrane transport properties and operating conditions have a major influence on the performance of OMDPs. Hence, accurate characterization of the membrane properties is critical to the prediction of OMDP performance under given operation conditions.

\section{Effects of operating conditions on ODMP process performance}

From Eqs. (1)-(5) it can be inferred that both operating conditions and membrane properties can substantially affect process performance. Results from a recent study revealed that water flux ranged from 6.5 to $8.3 \mathrm{~L} \mathrm{~m}^{-2} \mathrm{~h}^{-1}$ and that reverse salt flux ranged from 45 to $54 \mathrm{mmol} \mathrm{m}{ }^{-2} \mathrm{~h}^{-1}$ when the flow velocity varied independently from 0.4 to $1.1 \mathrm{~m} / \mathrm{s}$ on the feed and draw solution sides of the membrane [35].

The chemistry of the feed and draw solutions plays an important role in controlling the performance of ODMPs. While the composition and concentration of the draw solution solutes dictate its osmotic pressure, the actual driving force induced by the draw solution is also controlled by the viscosity of solution and diffusivity of the solutes [35]. For example, while the calculated osmotic pressure of $\mathrm{MgCl}_{2}$ may be very high at a specific concentration, its viscosity is higher and diffusivity is lower than those of $\mathrm{NaCl}$ [35], which can result in concentration polarization effects that reduce water flux through the membrane [41-44].

Temperature affects both the viscosity and the density of solutions and therefore can influence both the concentration and hydrodynamic boundary layers [43]. Temperature also affects the diffusivity of solutes. In ODMPs, feed and draw solution temperatures may be different, and they may slowly change due to heat transfer through the membrane as the streams flow through the membrane element. Results in Fig. 1 demonstrate that water flux in FO is strongly affected by the temperatures on both sides of the membrane and by draw solution concentrations. Therefore, temperature control during testing of ODMPs is also critical in determining and comparing the performance of existing and new membranes.

Polymeric membranes may also have a limited range of $\mathrm{pH}$ tolerance. Specifically, first generation ODMP membranes are made of cellulose acetate, which has a relatively narrow range of $\mathrm{pH}$ tolerance, usually between 4 and 8 [43]. Out of this range, the polymer hydrolyzes and

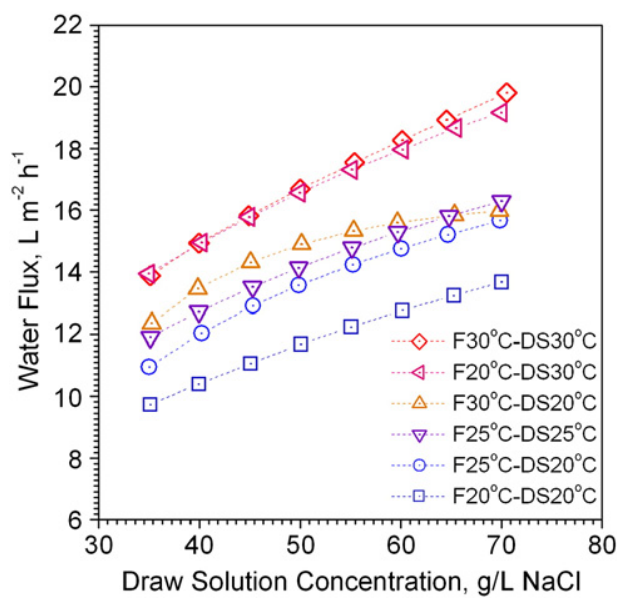

Fig. 1. Water flux as a function of draw solution concentration for different combinations of feed and draw solution temperatures. FO experiments were conducted with first generation HTI membrane (imbedded mesh) oriented with the support layer facing the draw solution (FO mode), no spacers in the flow channels, deionized water feed, and flow velocity of $0.2 \mathrm{~m} / \mathrm{s}$ [47]. leads to decreased membrane selectivity, which can result in higher water flux and lower salt rejection.

Last, when testing ODMP it is assumed that the driving force for mass transport through the membrane is only the chemical potential difference across the membrane and that hydraulic pressure does not contribute to mass transport. Even though membranes for ODMP are dense and semipermeable, small pressure differences across the membrane can influence water flux and solute rejection. Hence, it is also important to ensure that the transmembrane pressure across the membrane during testing of ODMP membranes approaches zero.

\section{Material and methods}

\subsection{Test apparatus}

\subsubsection{ODMP test apparatus}

The simplest apparatus for testing of ODMP membranes comprises a forward osmosis membrane cell, two low-pressure recirculation pumps (one for the feed and one for the draw solution), feed and draw solution tanks, and a hydraulic system of pipes, tubes, connectors, valves, and sensors (i.e., pressure gauges, flow meters, thermometers, and conductivity meters) to connect these components and to control and monitor liquid flows and conditions. The materials of all the wetted parts should be corrosion resistant (plastics or stainless steel). The membrane cell usually comprises two flow channels of the same dimensions, one on each side of the membrane. In PRO mode, the membrane is tested with low/ambient and similar pressures on both sides of the membrane.

Testing apparatus for ODMP may be more sophisticated and include a control system to maintain constant feed and draw solution concentrations, temperatures, and flow rates and to continuously record data. A schematic drawing of an advanced bench-scale ODMP test apparatus is illustrated in Fig. 2. For simple test setups, the draw solution reservoirs should be large enough to maintain nearly constant draw solution concentration throughout the experiment. The system should allow continuous or intermittent measurement of the concentrations, temperatures, and volumes of the feed and draw solutions.

\subsection{2. $R O$ test apparatus}

Most bench-scale systems for testing of pressure-driven membrane processes consist of a membrane test cell, high-pressure pump, feed tank, and a hydraulic system of pipes, tubes, connectors, pressure gauges, flow meters, and valves to connect these components and to control liquid flow (e.g., [45]). Again, the wetted parts must be of corrosionresistant materials as well as able to withstand elevated pressures. The cell typically has a flow channel on the feed side of the membrane and a permeate collector on the support side. Permeation rate can be measured by collecting permeate in a graduate cylinder, by measuring it with a rotameter or an electronic flow meter, or by collecting the permeate in a beaker placed on an analytical balance. Like in ODMP test systems, feed and permeate concentrations must be continuously or intermittently monitored and feed temperature, pressure, and flow velocity strictly controlled.

\subsection{Cross-flow velocity and flow rate}

Because different laboratories use different membrane cells, feed and draw solution flow rates have to be adjusted to achieve predetermined cross-flow velocity, which has direct influence on the mixing and mass transfer in the flow channel. The flow rate in each channel can be determined by multiplying the predetermined cross-flow velocity by the cross sectional area of the flow channel perpendicular to the flow direction. This method is applicable to both the FO/PRO and RO testing modes and test cells. Based on the operating conditions and dimensions of most ODMP test cells, $0.25 \mathrm{~m} / \mathrm{s}$ is the flow velocity that was selected for the feed and draw solutions in the round-robin study and for the proposed methodology. 


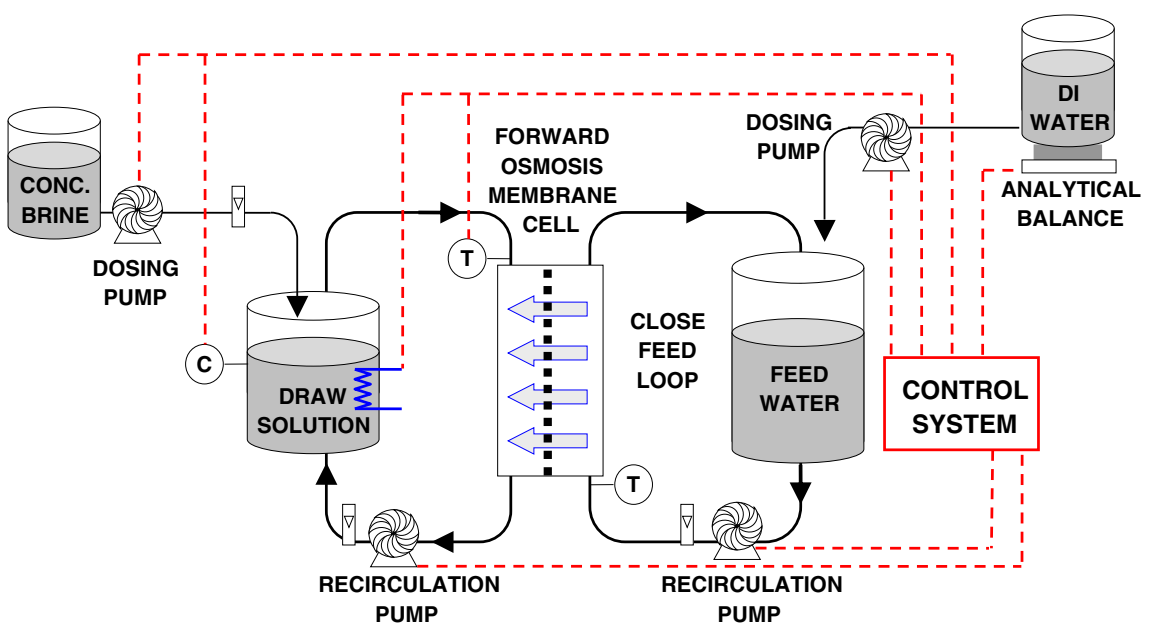

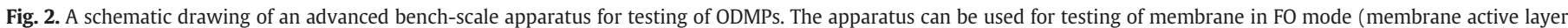
facing feed) or PRO mode (active layer facing draw solution).

While different flow channel geometries might generate different Reynolds number at the predetermined cross-flow velocity, it is assumed that the differences are minor. To avoid further variation, experiments should be conducted without turbulence-enhancing spacers in the feed (FO, PRO, and RO) and draw solution (FO and PRO) flow channels.

\subsection{Feed and draw solution temperatures}

Fluid temperature impacts the performance of almost all membrane processes. For the current round-robin study a temperature of $20{ }^{\circ} \mathrm{C}$ was chosen. This temperature is close to ambient room temperature in most laboratories and it is relatively easy to maintain by cooling only. If higher temperature was selected, both cooling and heating might be required to maintain constant temperature during FO and PRO experiments. During RO experiments heat is dissipated from the highpressure pump; thus, only external cooling is needed to maintain constant temperature.

\subsection{Feed and draw solution concentrations and concentration measurement}

For the FO and PRO testing in the round-robin study, a $1 \mathrm{M} \mathrm{NaCl}$ draw solution and deionized feed water were selected. This draw solution concentration and the concentration difference across the membrane produce a reasonable water flux in both high- and low-permeability ODMP membranes. With these feed and draw solutions it is also possible to accurately measure concentration changes in the feed stream due to reverse salt diffusion during the experiments [35].

Because of the bi-directional diffusion of solutes during osmosis, draw solution solutes will slowly accumulate in the feed stream during FO and PRO experiments, and they may get further concentrated due to permeation of feed water into the draw solution (dewatering of the feed stream). Simultaneously, the draw solution could become more diluted due to water permeation from the feed into the draw solution. Therefore, it is important to conduct performance tests with either a large volume of draw solution or with a control system that maintains draw solution concentration and feed volume constant during the course of the test. If a

Table 2

Operating conditions for testing of ODMP membranes in FO, PRO, and RO modes.

\begin{tabular}{|c|c|c|c|}
\hline Experimental conditions & Value & Units & Notes \\
\hline \multicolumn{4}{|c|}{ Testing modes: FO (active layer facing feed stream) and PRO (active layer facing DS stream) } \\
\hline Feed and DS temperatures & 20 & ${ }^{\circ} \mathrm{C}$ & \\
\hline $\begin{array}{l}\text { Draw solution } \\
\text { concentration }\end{array}$ & 1 & $\mathrm{M} \mathrm{NaCl}$ & $58.44 \mathrm{~g} / \mathrm{L} \mathrm{NaCl}$ \\
\hline Feed concentration & 0 & $\mathrm{M} \mathrm{NaCl}$ & Deionized water \\
\hline Feed and DS pH & Unadjusted & & As close to neutral and within the appropriate range for the polymer tested \\
\hline Feed and DS cross-flow velocity & 0.25 & $\mathrm{~m} / \mathrm{s}$ & $\begin{array}{l}\text { - Feed and DS flow rates defined by multiplying flow velocity by cross section area of the } \\
\text { flow channel perpendicular to flow direction } \\
\text { - No spacers in the feed or DS flow channel } \\
\text { - Co-current flow }\end{array}$ \\
\hline $\begin{array}{l}\text { Feed and DS pressures } \\
\text { Membrane orientation }\end{array}$ & $<0.2(3)$ & bar (psi) & $\begin{array}{l}\text { Keep as low as possible and similar on both sides of the membrane } \\
\text { Tests should be conducted in FO and PRO modes }\end{array}$ \\
\hline \multicolumn{4}{|c|}{ Testing modes: RO for determination of A and B (active layer facing feed stream) } \\
\hline Feed temperature & 20 & ${ }^{\circ} \mathrm{C}$ & \\
\hline Feed pressure & $8.62(125)$ & bar (psi) & $\begin{array}{l}\text { - For high permeability membranes, use } 4.82 \text { bar ( } 70 \mathrm{psi} \text { ) } \\
\text { - For both high and low permeability membranes, testing under more than one feed pressure } \\
\text { is recommended to validate membrane integrity }\end{array}$ \\
\hline Feed concentration & 0 & $\mathrm{mg} / \mathrm{L} \mathrm{NaCl}$ & Use deionized water for membrane compaction and for determination of water permeability coefficient $(A)$ \\
\hline & 2000 & $\mathrm{mg} / \mathrm{L} \mathrm{NaCl}$ & Use $\mathrm{NaCl}$ solution for rejection test and determination of salt permeability coefficient (B) \\
\hline Cross-flow velocity & 0.25 & $\mathrm{~m} / \mathrm{s}$ & $\begin{array}{l}\text { - Similar to FO testing } \\
\text { - Preferably without feed spacer }\end{array}$ \\
\hline
\end{tabular}


control system is not used and the feed reservoir is small, a mass balance and concentration factor calculations on the feed side might be required for accurate determination of reverse salt flux.

\section{5. $R O$ feed pressure and concentration}

Membranes for ODMP might be more delicate than commercial RO and NF membranes because in some ODMP the operating hydraulic pressure is much lower and mechanical support is not a major concern. Based on the performance and limitations of current ODMP membranes, we have suggested that the feed pressure during RO testing of ODMP membranes be limited to 8.62 bar (125 psi). During preparation for this study we observed that when testing high permeability membranes, this pressure is too high, producing water flux of approximately $100 \mathrm{~L} \mathrm{~m}^{-2} \mathrm{~h}^{-1}$. Thus, for high permeability membranes, lower feed pressures are recommended (Table 2 ).

For RO testing, a feed solution of $2000 \mathrm{mg} / \mathrm{L}$ ( $34.2 \mathrm{mM}$ ) NaCl was selected. Most membrane manufacturers use this solution for performance testing of their low- and intermediate-pressure RO membranes. Feed and permeate concentrations should be measured continuously or intermittently during testing. The simplest way to determine $\mathrm{NaCl}$ concentration is via electrical conductivity measurement.

\subsection{Membranes}

Two commercial ODMP membranes were selected for testing in this round-robin study. The first membrane is an asymmetric cellulose-based membrane from Hydration Technology Innovation (HTI, Albany, OR). This membrane has been used extensively in past OMDP studies, some of which are listed in Table 1. The second membrane tested is a thin film composite (TFC) polyamide membrane from Oasys Water (Boston, MA) [46].

\subsubsection{Membrane conditioning and installation}

Membranes used in ODMP have a dense, non-porous active layer and a porous support layer. When tested in FO mode, the membrane is always oriented with its active layer in contact with the feed stream/solution and the porous support layer in contact with the draw solution. When tested in PRO mode for the purpose of quantifying water and solute flux, the membrane is turned over with the support layer in contact with the feed stream and with no transmembrane pressure. It is important to consider that in the PRO testing mode support-layer fouling and concentrative internal concentration polarization (due to reverse salt diffusion) can negatively affect the performance of the process [39,47]. Organic and particulate matter may accumulate inside the porous structure of the support layer and reduce membrane permeability, and reverse salt flux will build up in the support layer and reduce the effective osmotic driving force. Thus, it is important to use very clean aqueous solutions during performance testing of ODMP membranes in PRO mode.

\subsubsection{Alcohol soaking preparation}

Prior to membrane testing, it is important to ensure that the membrane's porous support layer is fully water saturated $[16,48]$. This step is particularly important when testing TFC membranes that are less hydrophilic and might not be easily wetted upon exposure to water. Membrane hydration may be accomplished by pressurizing deionized water through the membrane using an RO testing apparatus, but is most typically accomplished by soaking the membrane in a $50 \%$ solution of methanol, ethanol, or isopropyl alcohol (IPA) for $5 \mathrm{~min}$. Following soaking, the membrane should be thoroughly rinsed in deionized water and stored in deionized water to maintain hydration. In this round-robin study only the TFC membrane was wetted with IPA prior to testing. The CTA membranes are usually well-hydrated when soaked in water and therefore additional hydration was not performed.

\subsection{Determination of membrane characteristic parameters}

\subsubsection{Determination of membrane active layer transport properties}

The intrinsic water permeability coefficient, $A$, and salt permeability coefficient, $B$, of the membranes were characterized in the RO test apparatus, according to the procedure described in an earlier study [9]. Brief$\mathrm{ly}$, the permeation rate was first normalized by the effective membrane area to yield the water flux, $J_{\mathrm{w}}$. The water permeability was then determined by dividing the water flux by the applied hydraulic pressure, $\Delta P$. That is, $A=J_{\mathrm{W}} / \Delta P$. The observed salt rejection, $R$, was calculated from the difference between the bulk feed $\left(c_{\mathrm{b}}\right)$ and permeate $\left(c_{\mathrm{p}}\right)$ salt concentrations, $R=1-c_{\mathrm{p}} / c_{\mathrm{b}}$. The salt permeability coefficient, $B$, was determined from $[41,43]$

$B=J_{\mathrm{W}}\left(\frac{1-R}{R}\right) \exp \left(-\frac{J_{\mathrm{W}}}{k}\right)$

where $k$ is the mass transfer coefficient for the crossflow channel of the RO membrane cell.

\subsubsection{Determination of membrane support structural parameters}

The structural parameter of the membrane support layer, $S$, determines the extent of internal concentration polarization in ODMPs and it is defined as the product of the thickness and tortuosity, divided by the porosity (i.e., $S=t \tau / \varepsilon$ ) of the membrane's porous support layer. Experiments in the ODMP test apparatus were employed to calculate $S$, following the protocol described in earlier studies $[9,18]$. The water flux, $J_{\mathrm{W}}$, using a $1 \mathrm{M} \mathrm{NaCl}$ draw solution and deionized water feed solution was measured with the membrane in FO mode (i.e., active layer facing the feed solution). The membrane support structural parameter was determined using [49]

$S=\frac{D_{\mathrm{S}}}{J_{\mathrm{W}}} \ln \left(\frac{B+A \pi_{D, b}}{B+J_{\mathrm{W}}+A \pi_{F, m}}\right)$

where $D_{\mathrm{S}}$ is the diffusivity of the draw solute, $\pi_{D, b}$ is the bulk osmotic pressure of the draw solution, and $\pi_{F, m}$ is the osmotic pressure at the membrane surface on the feed side (zero for deionized water feed).

\subsection{Summary of round-robin test conditions}

Based on data collected during literature survey and experience from years of research, standard experimental conditions were

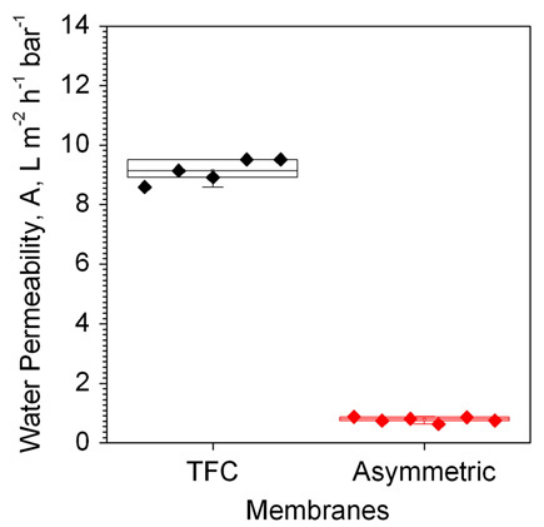

Fig. 3. Water permeability coefficients for the two ODMP membranes obtained from RO tests with deionized water feed. Operating conditions: feed pressure $8.62 \mathrm{bar}$ (125 psi), feed temperature $20^{\circ} \mathrm{C}$, and feed cross-flow velocity $0.25 \mathrm{~m} / \mathrm{s}$. Less than 7 points represent instances in which testing in specific laboratories failed or outliers were identified and removed. 

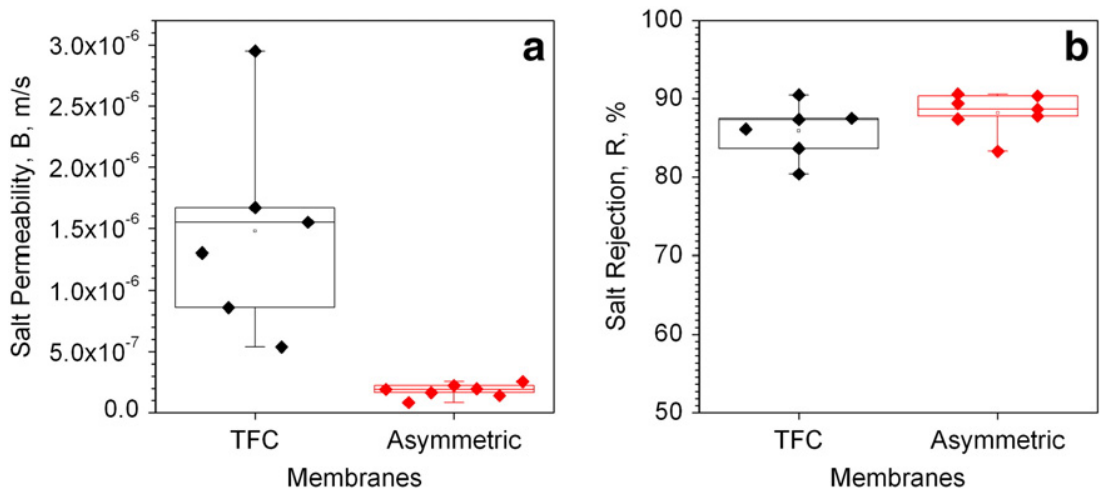

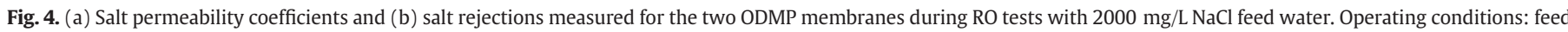
pressure 8.62 bar (125 psi), feed temperature $20^{\circ} \mathrm{C}$, feed flow velocity $0.25 \mathrm{~m} / \mathrm{s}$.

suggested for testing of ODMP membranes. These conditions were the basis for a round-robin testing campaign that was conducted during the summer of 2011. The test conditions are summarized in Table 2.

\section{Results and discussion}

Seven independent laboratories with experience in testing of ODMP membranes participated in the round-robin study. Membranes were acquired from a single cast and were cut and shipped at the same time to all participants with clear handling and testing instructions. At least one laboratory tested membranes with two different membrane cells. One laboratory compiled all the results and statistically evaluated the data.

\subsection{RO testing}

Both water flux and salt rejection were measured during RO testing of the two membranes. Results were used to calculate the water $(A)$ and salt $(B)$ permeabilities of the membranes. Water permeability coefficients determined during RO tests with deionized water feed are presented as box plots in Fig. 3 for the two membranes. Grubbs' test was performed to identify outliers at $5 \%$ significance level [50] and one data point was removed from the TFC dataset. Fig. 3 (and subsequent figures) includes all data points (average results), maximum and minimum values observed, average (hollow square in the middle of each box), 25 percentile (bottom of box), median (middle line in the box), and 75 percentile (top of box). Results indicate that the permeability of the TFC membrane is much higher than the water permeability of the asymmetric membrane and that the distribution of data is very narrow when testing water flux in RO mode.

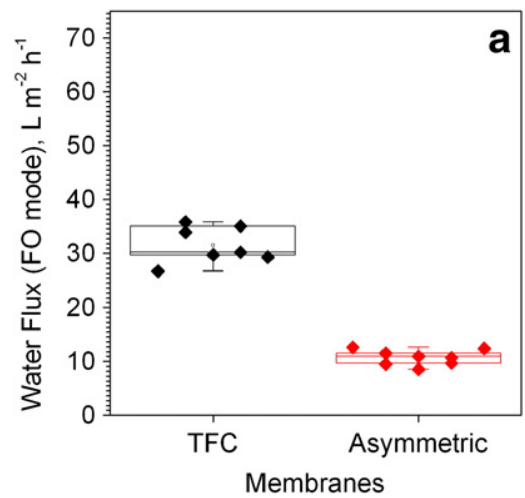

Concentration polarization effects need to be considered when calculating the salt permeability coefficient, $B$, from RO mode experiments [18]. Therefore, for each experiment the concentration polarization modulus was calculated, and the salt permeability of the membranes was determined based on the difference between the salt concentration at the membrane surface and the permeate concentration. Observed salt rejection was calculated based on feed and permeate bulk concentrations.

Salt permeability coefficients and salt rejection were determined during RO tests with feed solutions containing $2000 \mathrm{mg} / \mathrm{L} \mathrm{NaCl}$ and standard conditions defined in Table 2. Results from the participating laboratories are presented in Fig. 4a,b for the two membranes. Grubbs' test was performed to identify outliers; however, despite the large distribution of results for the TFC membrane, none of the data points was identified as an outlier. While the results of salt permeability coefficients for the TFC membrane in Fig. 4a look widely spread, the salt rejection by the TFC membranes ranged between 80.4 and $90.5 \%$ (Fig. 4b), with most of the data points above $86 \%$. These salt rejection results were very similar to the rejection by the asymmetric membrane.

\subsection{FO and PRO testing modes}

\subsubsection{Water flux}

Water flux and reverse salt flux were measured for both membranes in the FO and PRO modes under the conditions summarized in Table 2. Water flux through the two membranes in FO mode and PRO mode is shown in Fig. 5a,b, respectively. Grubbs' test was performed to identify outliers in the data [50]. Only one data point was identified as an outlier and was excluded from the dataset.

It is apparent from the data that water flux through the asymmetric cellulose acetate membrane is lower in both testing modes (FO and PRO); however, the data are less scattered compared to those from

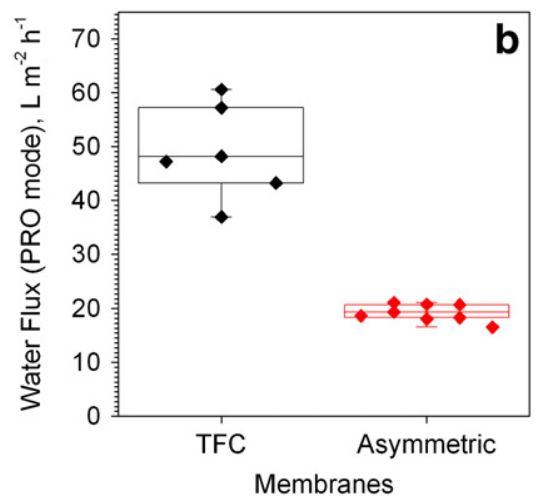

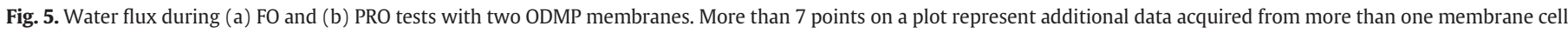

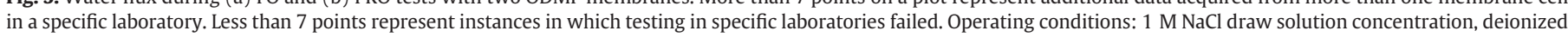
water feed, $0.25 \mathrm{~m} / \mathrm{s}$ feed and draw solution flow velocities, and $20{ }^{\circ} \mathrm{C}$ feed and draw solution temperatures. 

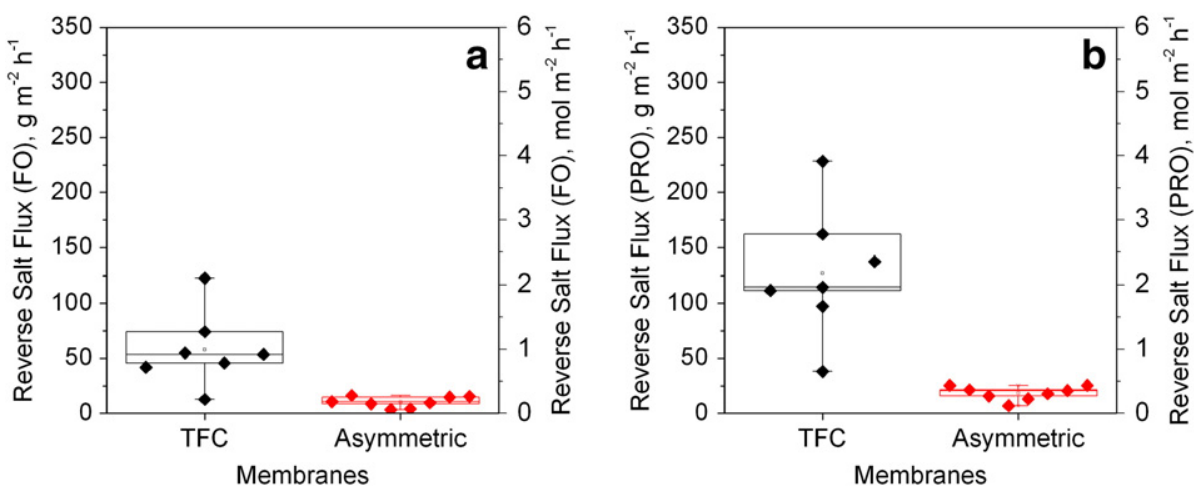

Fig. 6. Reverse salt flux during (a) FO and (b) PRO tests with two ODMP membranes. Operating conditions as detailed in Table 2 and in the caption of Fig. 5.

the TFC membranes. The TFC membrane employs an exceedingly thin RO-type polyamide active layer supported with a thin and highly porous support layer, resulting in much higher water flux compared to asymmetric membranes. The larger variability of the TFC membrane may be attributed to dewetting of the hydrophobic support layer or by small defect formation caused by variable handling and loading of the membrane between the various laboratories.

\subsubsection{Reverse salt flux}

Salt flux was calculated by multiplying the rate of change of feed concentration with time by the volume of the feed solution and then dividing by the area of the membrane, expressed in units of $\mathrm{g} \mathrm{m}^{-2} \mathrm{~h}^{-1}$ or mol m $\mathrm{m}^{-2} \mathrm{~h}^{-1}$. Reverse salt fluxes as a function of membranes used and operating mode are presented in Fig. 6a for FO and in Fig. 6b for PRO. In agreement with the results presented in Fig. 4, reverse salt flux through the asymmetric membrane is lower than that through the TFC membrane. Furthermore, reverse salt flux is higher during PRO testing compared to FO, mainly due to internal concentration polarization effects. It is also important to note that because the ratio between solute reverse flux and water flux is constant [36,40] (and Eq. (5) here), higher water flux in PRO may contribute to higher salt flux. The spread of results was also larger for the TFC membrane compared to the asymmetric membrane. Grubbs' test was performed, but none of the data points was identified as an outlier.

\subsubsection{Structural parameter}

Results from membrane performance tests were used to calculate the structural parameter $(S=t \tau / \varepsilon)$ of the porous support layer of the two ODMP membranes employed in this study. As illustrated in Fig. 7, the average structural parameter for the TFC membrane is lowerprimarily due to its thinner support layer and higher porosity.

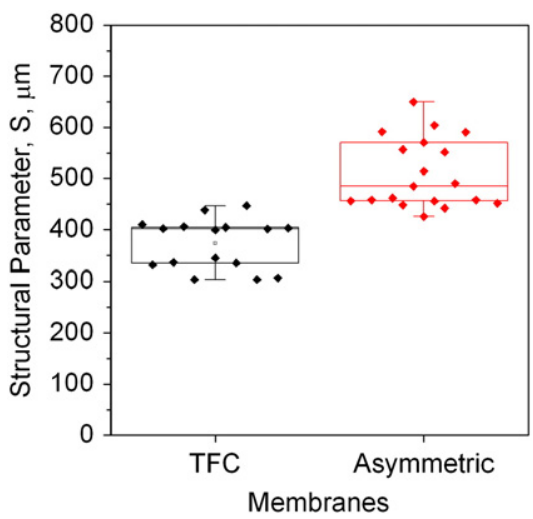

Fig. 7. Structural parameters of the two ODMP membranes. Operating conditions as detailed in Table 2 and in the caption of Fig. 5.
The structural parameter results are scattered for both the asymmetric and TFC membranes but the average value for the asymmetric membrane is generally similar to results obtained in previous studies [36,37]. It is important to note that parameters used in calculating the structural parameter are obtained from both FO and RO experiments, and in most cases the tests are conducted with different membrane samples, which can introduce variability in results due to differences in membrane properties. That said, the standard deviation of results from each laboratory that participated in the study was low.

\section{Concluding remarks}

The performance of two commercially available ODMP membranes was evaluated in FO, PRO, and RO modes in seven independent laboratories. It was demonstrated that by following a standard testing procedure, similar results can be obtained and easier comparison between past, present, and future ODMP membranes can be achieved. This is especially true for more mature membranes that are commercially manufactured extended time and are more robust (the asymmetric membrane in this study).

Our results further indicate that membrane integrity plays an important role in membrane performance testing. New generation TFC ODMP membranes are more difficult to evaluate; their thin active and support layers and their high permeability introduce potential integrity problems and considerable concentration polarization (both external and internal) effects due to high water flux. For newly developed TFC ODMP membrane it is important to use membrane characterization techniques (e.g., scanning electron microscopy, atomic force microscopy, porosity test, etc.) prior to performance testing in order to determine and assure membrane integrity. TFC membranes should be tested at lower hydraulic pressures in RO mode during determination of water and salt permeabilities to reduce the effects of external concentration polarization. Conducting FO and RO tests with the same membrane sample increases the accuracy of parameters used for calculating the structural parameter of the membrane support layer.

A similar testing procedure should be developed for future hollow fiber and capillary ODMP membranes. Most operating conditions suggested in this study will be identical with a few modifications. Cross-flow velocity inside the capillaries/fibers will have to be adjusted to maintain similar flow velocity but with no development of hydraulic pressure due to pressure drop in the fibers. It will likely be difficult to test capillary membranes under pressure, and therefore, A and B will have to be indirectly calculated from results of FO and PRO experiments.

\section{Acknowledgment}

The authors acknowledge the California Department of Water Resources (Grant 46-7446-R-08) for partial support of this study. 


\section{References}

[1] T.Y. Cath, A.E. Childress, M. Elimelech, Forward osmosis: principles, applications, and recent developments, J. Membr. Sci. 281 (2006) 70-87.

[2] T.Y. Cath, N.T. Hancock, C.D. Lundin, C. Hoppe-Jones, J.E. Drewes, A multi barrier hybrid osmotic dilution process for simultaneous desalination and purification of impaired water, J. Membr. Sci. 362 (2010) 417-426.

[3] L.A. Hoover, W.A. Phillip, A. Tiraferri, N.Y. Yip, M. Elimelech, Forward with osmosis: emerging applications for greater sustainability, Environ. Sci. Technol. 45 (2011) 9824-9830.

[4] A. Achilli, A.E. Childress, Pressure retarded osmosis: from the vision of Sidney Loeb to the first prototype installation-review, Desalination 261 (2010) 205-211.

[5] J. Su, Q. Yang, J.F. Teo, T.-S. Chung, Cellulose acetate nanofiltration hollow fiber membranes for forward osmosis processes, J. Membr. Sci. 355 (2010) 36-44.

[6] L. Setiawan, R. Wang, K. Li, A.G. Fane, Fabrication of novel poly(amide-imide) forward osmosis hollow fiber membranes with a positively charged nanofiltration-like selective layer, J. Membr. Sci. 369 (2011) 196-205.

[7] J. Wei, C. Qiu, C.Y. Tang, R. Wang, A.G. Fane, Synthesis and characterization of flat-sheet thin film composite forward osmosis membranes, J. Membr. Sci. 372 (2011) 292-302

[8] Y. Yu, S. Seo, I.-C. Kim, S. Lee, Nanoporous polyethersulfone (PES) membrane with enhanced flux applied in forward osmosis process, J. Membr. Sci. 375 (2011) 63-68.

[9] A. Tiraferri, N.Y. Yip, W.A. Phillip, J.D. Schiffman, M. Elimelech, Relating performance of thin-film composite forward osmosis membranes to support layer formation and structure, J. Membr. Sci. 367 (2011) 340-352.

[10] K.Y. Wang, T.-S. Chung, J.-J. Qin, Polybenzimidazole (PBI) nanofiltration hollow fiber membranes applied in forward osmosis process, J. Membr. Sci. 300 (2007) 6-12.

[11] S. Zhang, K.Y. Wang, T.-S. Chung, H. Chen, Y.C. Jean, G. Amy, Well-constructed cellulose acetate membranes for forward osmosis: minimized internal concentration polarization with an ultra-thin selective layer, J. Membr. Sci. 360 (2010) 522-535.

[12] M. Sairam, E. Sereewatthanawut, K. Li, A. Bismarck, A.G. Livingston, Method for the preparation of cellulose acetate flat sheet composite membranes for forward osmosis-desalination using $\mathrm{MgSO}_{4}$ draw solution, Desalination 273 (2011) 299-307.

[13] C. Qiu, L. Setiawan, R. Wang, C.Y. Tang, A.G. Fane, High performance flat sheet forward osmosis membrane with an NF-like selective layer on a woven fabric embedded substrate, Desalination 287 (2012) 266-270.

[14] Q. Yang, K.Y. Wang, T.-S. Chung, A novel dual-layer forward osmosis membrane for protein enrichment and concentration, Sep. Purif. Technol. 69 (2009) 269-274.

[15] C. Qiu, S. Qi, C.Y. Tang, Synthesis of high flux forward osmosis membranes by chemically crosslinked layer-by-layer polyelectrolytes, J. Membr. Sci. 381 (2011) 74-80.

[16] J.T. Arena, B. McCloskey, B.D. Freeman, J.R. McCutcheon, Surface modification of thin film composite membrane support layers with polydopamine: enabling use of reverse osmosis membranes in pressure retarded osmosis, J. Membr. Sci. 375 (2011) 55-62.

[17] N.-N. Bui, M.L. Lind, E.M.V. Hoek, J.R. McCutcheon, Electrospun nanofiber supported thin film composite membranes for engineered osmosis, J. Membr. Sci. 385-386 (2011) 10-19.

[18] N.Y. Yip, A. Tiraferri, W.A. Phillip, J.D. Schiffman, M. Elimelech, High performance thin-film composite forward osmosis membrane, Environ. Sci. Technol. 44 (2010) 3812-3818.

[19] N.Y. Yip, A. Tiraferri, W.A. Phillip, J.D. Schiffman, L.A. Hoover, Y.C. Kim, M. Elimelech, Thin-film composite pressure retarded osmosis membranes for sustainable power generation from salinity gradients, Environ. Sci. Technol. 45 (2011) 4360-4369.

[20] X. Song, Z. Liu, D.D. Sun, Nano gives the answer: breaking the bottleneck of internal concentration polarization with a nanofiber composite forward osmosis membrane for a high water production rate, Adv. Mater. 23 (2011) 3256-3260.

[21] R. Wang, L. Shi, C.Y. Tang, S. Chou, C. Qiu, A.G. Fane, Characterization of novel forward osmosis hollow fiber membranes, J. Membr. Sci. 355 (2010) 158-167.

[22] K.Y. Wang, R.C. Ong, T.-S. Chung, Double-skinned forward osmosis membranes for reducing internal concentration polarization within the porous sublayer, Ind. Eng. Chem. Res. 49 (2010) 4824-4831.

[23] N. Widjojo, T.-S. Chung, M. Weber, C. Maletzko, V. Warzelhan, The role of sulphonated polymer and macrovoid-free structure in the support layer for thin-film composite (TFC) forward osmosis (FO) membranes, J. Membr. Sci. 383 (2011) 214-223.
[24] S. Chou, R. Wang, L. Shi, Q. She, C. Tang, A.G. Fane, Thin-film composite hollow fiber membranes for pressure retarded osmosis (PRO) process with high power density, J. Membr. Sci. 389 (2012) 25-33.

25] L. Shi, S.R. Chou, R. Wang, W.X. Fang, C.Y. Tang, A.G. Fane, Effect of substrate structure on the performance of thin-film composite forward osmosis hollow fiber membranes, J. Membr. Sci. 382 (2011) 116-123.

[26] J. Wei, X. Liu, C. Qiu, R. Wang, C.Y. Tang, Influence of monomer concentrations on the performance of polyamide-based thin film composite forward osmosis membranes, J. Membr. Sci. 381 (2011) 110-117.

[27] S. Zhang, K.Y. Wang, T.-S. Chung, Y.C. Jean, H. Chen, Molecular design of the cellulose ester-based forward osmosis membranes for desalination, Chem. Eng. Sci. 66 (2011) 2008-2018.

[28] Q. Saren, C.Q. Qiu, C.Y. Tang, Synthesis and characterization of novel forward osmosis membranes based on layer-by-layer assembly, Environ. Sci. Technol. 45 (2011) 5201-5208.

[29] Q. Yang, K.Y. Wang, T.-S. Chung, Dual-layer hollow fibers with enhanced flux as novel forward osmosis membranes for water production, Environ. Sci. Technol. 43 (2009) 2800-2805.

[30] J.R. McCutcheon, M. Elimelech, Influence of concentrative and dilutive internal concentration polarization on flux behavior in forward osmosis, J. Membr. Sci. 284 (2006) 237-247.

[31] J.R. McCutcheon, M. Elimelech, Modeling water flux in forward osmosis: implications for improved membrane design, AIChE J. 53 (2007) 1736-1744.

[32] G.D. Mehta, S. Loeb, Internal polarization in the porous substructure of a semipermeable membrane under pressure-retarded osmosis, J. Membr. Sci. 4 (1978) 261.

[33] G.T. Gray, J.R. McCutcheon, M. Elimelech, Internal concentration polarization in forward osmosis: role of membrane orientation, Desalination 197 (2006) 1-8.

[34] N.T. Hancock, W.A. Phillip, M. Elimelech, T.Y. Cath, Bidirectional permeation of electrolytes in osmotically driven membrane processes, Environ. Sci. Technol. 45 (2011) 10642-10651.

[35] N.T. Hancock, T.Y. Cath, Solute coupled diffusion in osmotically driven membrane processes, Environ. Sci. Technol. 43 (2009) 6769-6775.

[36] W.A. Phillip, J.S. Yong, M. Elimelech, Reverse draw solute permeation in forward osmosis: modeling and experiments, Environ. Sci. Technol. 44 (2010) 5170-5176

[37] J.S. Yong W. A. Phillip, M. Elimelech, Coupled reverse draw solute permeation and water flux in forward osmosis with neutral draw solutes, J. Membr. Sci. 392-393 (2012) 9-17.

[38] X. Jin, C.Y. Tang, Y. Gu, Q. She, S. Qi, Boric acid permeation in forward osmosis membrane processes: modeling, experiments, and implications, Environ. Sci. Technol. 45 (2011) 2323-2330.

[39] A. Achilli, T.Y. Cath, A.E. Childress, Power generation with pressure retarded osmosis: an experimental and theoretical investigation, J. Membr. Sci. 343 (2009) 42-52.

[40] C.Y. Tang, Q. She, W.C.L. Lay, R. Wang, A.G. Fane, Coupled effects of internal concentration polarization and fouling on flux behavior of forward osmosis membranes during humic acid filtration, J. Membr. Sci. 354 (2010) 123-133.

[41] R.W. Baker, Membrane Technology and Applications, 2nd edition John Wiley \& Sons, Ltd., New York, NY, 2004.

[42] E.L. Cussler, Diffusion Mass Transfer in Fluid Systems, 2nd edition Cambridge University Press, 1997.

[43] M. Mulder, Basic Principles of Membrane Technology, 2nd edition, 2nd edition Kluwer Academic Publishers, Dordrecht, The Netherlands, 2001.

44] A. Achilli, T.Y. Cath, A.E. Childress, Selection of inorganic-based draw solutions for forward osmosis applications, J. Membr. Sci. 364 (2010) 233-241.

[45] Bench Scale Equipment Resources, http://www.sterlitech.com/bench-scaleequipment/cross-and-tangential-flow-test-cells/sepa-cf-ii.html2012.

[46] R.L. McGinnis, G. McGurgan, Forward osmosis membranes (patent application), WIPO (2010) PCT/US2010/046521 (WO/2011/028541).

[47] R.W. Holloway, Forward Osmosis for Concentration of Anaerobic Digester Centrate, University of Nevada, Reno, 2006.

[48] J.R. McCutcheon, M. Elimelech, Influence of membrane support layer hydrophobicity on water flux in osmotically driven membrane processes, J. Membr. Sci. 318 (2008) $458-466$.

[49] S. Loeb, L. Titelman, E. Korngold, J. Freiman, Effect of porous support fabric on osmosis through a Loeb-Sourirajan type asymmetric membrane, J. Membr. Sci. 129 (1997) 243-249.

[50] NIST/USDC, Engineering and Statistics Handbook, http://www.itl.nist.gov/div898/ handbook/2010. 